\title{
The Multiphasic and Dynamic Nature of Flow in Adventure Experiences
}

\author{
Susan Houge Mackenzie \\ University of Idaho \\ Ken Hodge \\ Mike Boyes \\ University of Otago, Dunedin, New Zealand
}

\begin{abstract}
This study evaluated phases of adventure experiences by identifying flow and reversal theory states over a 3-day white-water river surfing course. Data were collected with novice river surfers $(n=5)$ via in-depth qualitative interviews using head-mounted video cameras. Findings suggested that "opposing" experiential phases (i.e., telic and paratelic) may be symbiotic in adventure experiences and may facilitate flow experiences. These results may account for the dynamic nature of enjoyment, flow, and motivational states within adventure experiences. Future research should seek to validate the phasic models presented herein and evaluate their potential applicability to other adventurous activities.
\end{abstract}

KEYWORDS: Flow, reversal theory, adventure, experiential phases, qualitative

Susan Houge Mackenzie is an assistant professor in the Department of Movement Sciences at the University of Idaho.

Dr. Ken Hodge is a professor and Dr. Mike Boyes is an associate professor at the School of Physical Education, University of Otago, Dunedin, New Zealand.

This study was conducted as a portion of Dr. Houge Mackenzie's doctoral dissertation.

Please send correspondence to smackenzie@uidaho.edu 
Past research has divided recreational experiences into phases and has highlighted the dynamic and multiphasic nature of wilderness experiences (Borrie \& Roggenbuck, 2001), long-distance walking (Breejen, 2007), and outdoor adventure experiences (McIntyre \& Roggenbuck, 1998). As adventure is a particular subset of leisure and recreational experiences, this broader literature provides a starting point from which to better understand adventure experiences. This body of research suggested that adventure experiences may occur in distinct phases and that changes in states of mind during these phases are affected by contextual variables (e.g., activity, environment) and person variables (e.g., motivational and mood states). Moreover, researchers concluded that the identification of "special peak moments," more than ordinary events or the passage of time, might reveal meaningful transitions in lived experiences and define significant trip phases (Borrie \& Roggenbuck, 2001, p. 225). Research on flow states, which have been robustly documented as "special" or "optimal" experiences (e.g., Nakamura \& Csikszentmihalyi, 2005), has also highlighted the need to examine how flow experiences fluctuate over time via repeated measurements (Ceja \& Navarro, 2009). The current study addressed these respective gaps in the adventure and flow literatures via a multiday qualitative investigation of adventure-based flow experiences. This social-psychological investigation was part of a larger research project that incorporated reversal theory (Apter, 2001) states to operationalize and explain motivational and experiential fluctuations during adventure activities (Houge Mackenzie, Hodge, \& Boyes, 2011). This study was unique because it examined motivational and experiential fluctuations during adventure activities through a reversal theory lens.

\section{The Multiphasic Nature of Adventure Experiences}

Researchers have hypothesized that leisure experiences are dynamic and emerge via interactions between the participant and his or her environment on emotional and cognitive levels (Lee \& Shafer, 2002, p. 290). Lee, Datillo, and Howard (1994) asserted the importance of examining the quality of leisure experiences and called for real-time investigations of leisure that accounted for dynamic elements such as intensity, duration, motivational components, and meaning. Researchers have also conceptualized recreational experiences as "emergent" rather than linear; emphasized the need to understand their dynamic, multiphasic nature (e.g., McIntyre \& Roggenbuck, 1998; Paterson, Watson, Williams, \& Roggenbuck, 1998); and used temporal phases (e.g., entry, immersion, exit), attentional focus, activity and space, and mood measures (e.g., Borrie \& Roggenbuck, 2001; Lee et al., 1994; McIntyre \& Roggenbuck, 1998) to investigate the multiphasic nature of recreation experiences. An emergent model of experience was supported by research that found that people "set out to consume an extended sequence of relaxing feelings dotted with peaks of excitement" rather than a singular experiential outcome (Hull, Stewart, \& Yi, 1992, p. 250). Although Hull et al. (1992) identified fluctuations in experience patterns (e.g., level of engagement) as useful units of analysis, these authors highlighted the "considerable need" to identify and operationalize meaningful and salient dimensions of leisure phases. Based on this literature, and the identified need to further investigate fluctuations in affective states during 
recreational experiences, the term multiphasic was operationalized in this study as distinct affective states in either a regular, recurring cycle or a course of development.

Adventure research across settings has further supported these leisure findings (e.g., Apter \& Batler, 1997; Borrie \& Roggenbuck, 2001). Specifically, research in white-water settings has identified that fluctuations in positive (e.g., flow) and negative (e.g., anxiety) emotional states occur regularly throughout white-water experiences, particularly in relation to perceptions of personal competence and challenges (Jones, Hollenhorst, \& Perna, 2003). In these studies, measures of flow or reversal theory states were often used to identify significant emotional and/or motivational changes during a white-water activity. The results and measurement tools used in these studies supported the contention that key phases of adventure experiences should be (a) operationalized via meaningful transitions in lived experiences (e.g., motivational states, emotions, and degree of engagement) and (b) measured throughout an experience. Notwithstanding the theoretical and methodological contributions of these studies, little research has purposefully explored the multiphasic and dynamic nature of adventure experiences over a multiday period, particularly with regard to flow and reversal theory states. Consequently, the motivational dynamics within adventure experiences are not yet fully understood. The current study sought to deepen our understanding of adventure experiences by using two robust psychological theories to explain both how and why different affective states unfold within an adventure experience. Understanding relationships among key psychological states may elucidate the holistic nature of adventure experiences.

\section{Flow States}

Qualitative investigations of intrinsic motivation and enjoyment identified the state of flow as an exceptionally pleasant experiential state that provided a central motivation for participation in adventure activities (e.g., Csikszentmihalyi \& Csikszentmihalyi, 1990). The following nine dimensions distinguish flow from other experiential states: challenge-skill balance, merging of action and awareness, clear goals, unambiguous feedback, total concentration on the current task, sense of control, loss of self-consciousness, transcendence of time, and autotelic experience (Jackson \& Eklund, 2004).

Flow represents one important phase of memorable, multiphasic experiences. Studies of farming communities, urban workers, and professional dancers in Italy, for instance, revealed that daily activities had clear phases in which flow was more likely to occur (Massimini, Csikszentmihalyi, \& Delle Fave, 1988). Rather than resulting from the passage of a fixed time, flow was preceded by key motivational antecedents (e.g., psychological security, serenity, enthusiasm). These reflections suggested that flow may be influenced by context more than time and may be just one significant phase of an individual's overall experience. Common flow methodologies, such as the Experience Sampling Method (ESM; Csikszentmihalyi \& Larson, 1987), have also documented various phases of daily life based on their subjective quality. As little research has sought to examine patterns of motivation related to flow, Ceja and Navarro (2009) drew upon Chaos theory to explore whether flow presented a nonlinear dynamic. This study suggested not only that 
flow was dynamic but also that important patterns of motivation could only be identified using multiple data collections across time.

\section{Reversal Theory States and Protective Frames}

Reversal theory states provide an innovative way to operationalize various dynamic motivational components over time in adventure experiences. Reversal theory approaches to understanding inter- and intrapersonal differences in subjective experience have been empirically validated in sport and adventure studies (e.g., Apter, 1989, 1992, 2001; Apter \& Batler, 1997; Kerr, 1991, 1999a, 1999b; Kerr \& Cox, 1991; Kerr, Fujiyama, \& Campano, 2002), as well as studies of addiction (O'Connell, Cook, Gerkovich, Potocky, \& Swan, 1990), stress response (Martin, Kuiper, Olinger, \& Dobbin, 1987), play (Kerr \& Apter, 1991), enjoyment of humor (Wyer \& Collins, 1992), soccer hooliganism (Kerr, 1994), and cardiovascular risk (Svebak, Nordby, \& Ohman, 1987).

Reversal theory is a general model of human experience and motivation, which proposes that psychological needs occur in opposing pairs. For example, the need for relaxation is opposed by the need for excitement and the need for serious achievements is opposed by the need for playfulness and immediate enjoyment (Apter, Mallows, \& Williams, 1998). Reversal theorists contend that (a) current psychological needs are determined by metamotivational states, (b) considerable changes in motivations and emotions are instigated via regular reversals between opposing metamotivational states, and (c) alternatively satisfying opposing needs through frequent reversals promotes psychological health (Frey, 1999).

Metamotivational states are frames of mind, or higher order motivation levels, which determine how a person interprets her or his situation at any given time. The goal of a metamotivational state is to feel a certain way, rather than necessarily obtaining a tangible outcome. A metamotivational state can be conceptualized as a proverbial pair of rose-colored glasses (Apter, 1992); a person always "sees" or, more aptly, "feels" an experience in the context of her or his dominant metamotivational lens. Another way of conceptualizing metamotivation is as the background, or "wallpaper," of experience. Although not the focus of an individual's attention, the peripheral presence of a metamotivational state colors the overall experience (Lachenicht, 1988). Although reversal theory encompasses four pairs of opposing metamotivational states, this investigation focused on the telic and paratelic states. This pair of states addresses the same emotional states as flow theory (i.e., anxiety, excitement, boredom, and relaxation) and accounts for differential interpretations of intense emotional arousal, which characterize adventure experiences. Moreover, the greatest depth of research literature has been devoted to the telic-paratelic pair.

In the telic state individuals feel serious, goal oriented, and arousal avoidant, whereas individuals in the paratelic state feel playful, spontaneous, and arousal seeking (Apter, 2001). In the telic state, current activity is seen as a means to an important end beyond the present moment and thoughts are directed to planning for future outcomes (Apter, 1982). Excessive arousal due to difficulties in achieving outcome-oriented goals will thus produce anxiety or fear. Pleasant relaxation, or calmness, is proposed to result from lower arousal levels that are preferred in 
the telic state. In the paratelic state, arousal levels are subjectively experienced in direct opposition to the telic state pattern. High arousal is experienced as excitement, whereas low arousal is boring. A lack of serious goals and a present-moment, activity-oriented focus defines the paratelic state. In this playful state, activities are pursued as ends within themselves and attentional focus is absorbed in the process-oriented goals of the activity

Reversals between the telic and paratelic states are contingent upon the presence or absence of protective frames (Apter, 1993, p. 28). As the name implies, a protective frame provides feelings of protection from the presence of danger (e.g., due to confidence in oneself, others, or equipment). When the protective frame is active (in the paratelic state), people experience challenges and heightened arousal as exciting; when the protective frame is lacking (in the telic state), people experience challenges and heightened arousal as anxiety.

\section{Reversal Theory Constructs and Distinct Flow Experiences}

In seminal reversal theory literature, Apter (1982) identified commonalities between autotelic flow descriptions and the paratelic state. He classified flow as an optimal paratelic experience that represented one point along a spectrum of potential paratelic emotions (e.g., boredom and excitement); support for this conception of flow as a paratelic experience was also recognized in sport literature (Kerr, 1985, 1989). Based on the hypothesis that telic anxiety would inhibit flow, Kerr (1989) and Apter (1982) concluded that flow experiences were optimally exciting experiences of heightened arousal exclusive to the paratelic state. Rea (1993) conceptualized the additional possibility of telic flow as "relaxing flow" (p. 79) and identified flow as the optimal state of either telic relaxation or paratelic excitement. Qualitative descriptions from flow research on surgeons (Csikszentmihalyi, 1975) and cross-cultural educational experiences (Carli, Delle Fave, \& Massimini, 1988) were proposed to reflect these distinct but equally enjoyable flow states, and recent adventure-based research further strengthened links between the telic-paratelic pair and distinct flow states (Houge Mackenzie, Hodge, \& Boyes, 2011).

Reversal theory has been used to understand subjective experiences across a range of adventure and leisure activities (e.g., Cogan \& Brown, 1999; Pain \& Kerr, 2004). Previous reversal theory research successfully tracked changes in metamotivational states over time among white-water kayakers by measuring fluctuations in the telic and paratelic states (Males, 1999). The current study expanded this body of research by examining adventure-based flow experiences multiphasically within a reversal theory framework. It was hoped that incorporating established theoretical constructs and measurement tools would expand upon past multiphasic research by identifying and operationalizing key phases of metamotivational states, emotions, and flow within adventure experiences. This investigation ultimately sought to increase the specificity and predictive value of multiphasic models and to provide useful measurement approaches for future research in this area. These objectives lead to the formation of the following research question: How do phases of adventure experiences unfold with regard to (a) the telic and paratelic states and (b) the flow states? 


\section{Method}

Because an individual's motives during an experience are dynamic, researchers have argued that they are best captured within the parameters of a discrete experience (Breejen, 2007). Furthermore, examining phenomena of interest over a time and space continuum has been suggested to "improve one's ability to provide insight, and perhaps disentangle, the complex interactions of time, setting, and person" (Stewart \& Hull, 1996, p. 5). In light of this literature and the call for repeated measurements of flow over time (Ceja \& Navarro, 2009), a 3-day study was conducted in which 15 in-depth qualitative interviews (three per person) were conducted with participants on an introductory white-water training course. Prospective data collected via head-mounted cameras worn by participants were used to facilitate interviews.

\section{Participants and Sampling}

A sample of five ( $n=5$, mean age $=25$ years, three males, two females) novice white-water river surfing participants (from a larger group of 10 enrolled in the 3-day course) were purposefully selected for this study. Selection was based on previous research that found (a) novice participants experienced greater fluctuations in mood throughout a multiday outdoor experience (Breejen, 2007) and (b) white-water participants experienced significant fluctuations in mood throughout a single experience (e.g., Jones et al., 2003). We chose to recruit novice white-water river surfers due to the inherent challenges and risks posed by the environment (i.e., white-water river rapids) and participants' relative lack of experience and skill in this activity. River surfing is an activity in which participants navigate river rapids and surf river waves while lying headfirst on a bodyboard. Whitewater is graded by level of difficulty ranging from grade 1 (free passage, fast-moving water with few obstructions) to grade 6 (generally speaking impassible, possibly navigable at certain water levels; Ferrero, 2006).

The five novices selected for qualitative data collection via daily interviews were cittzens of New Zealand (Jenna, Nina, Dan), Canada (Mitch), or India (Ten$\mathrm{zin}^{1}$ ) who were purposefully selected to represent a cross section of the outdoor and white-water experience present within the larger group of 10 . Head-mounted digital video cameras were used to obtain prospective data during the 3 -day course as this method had facilitated significantly greater immersion and specificity of recall in past research (Omodei \& McLennan, 1994). Individual video footage was compiled and replayed during 25- to 55-minute interviews at the end of each day. Participant interviews were rotated daily to minimize order effects. During the interviews, participants watched personal video recordings and were asked to narrate this footage with their thoughts and feelings as the experience unfolded. Only after participants had related their experiences inductively were they probed as to whether reversal theory or flow constructs represented a part of their experience (deductive data) and, if so, what role these constructs may have played within their overall experience.

\footnotetext{
'All names are pseudonyms.
} 


\section{Data Analysis}

Interviews were transcribed verbatim and perused for key themes. Themes were highlighted along with notes relating them to reversal theory or flow constructs where applicable. These raw data quotes and themes were then color-coded and grouped into related themes in extensive summarizing documents that diagrammed episodes sequentially with supporting quotes. Any unique themes from an interview, including emergent themes, were highlighted via the color-coding system. These documents also formed the basis for theoretical visual models that accompanied individual case studies.

In qualitative research, the quality of data collected is dependent on the extent to which the investigator can establish trustworthiness (e.g., Denzin \& Lincoln, 2005). Providing a "thick description" of sampling and interview procedures here allows readers to evaluate the credibility of these methods. In addition, a university academic well versed in reversal theory and adventure pursuits conducted an audit trail to evaluate the credibility of these analyses. Member checking was conducted to further establish trustworthiness. Any inconsistent or illogical statements were addressed verbally at the end of the interview and in a written format following the interview. In the member checking process, participants were given the opportunity to modify or elaborate upon previous statements. Follow-up member checks (i.e., 10-15 page summaries including visual models and quotes) were delivered within 10 days to allow participants to review and amend data interpretations.

The creation of individual case studies began only after both the interviewer and the participant were satisfied with the accuracy and representativeness of raw descriptors and emergent themes generated during the interview. Evidence of flow and reversal theory constructs were identified through the use of established coding instruments such as the Metamotivational State Coding Scale (MSCS; O'Connell, Potocky, Cook, \& Gerkovich, 1991) and the Flow State Scale (FSS; Jackson \& Eklund, 2004).

Individual case studies were created based on content analysis of each participant's three interview transcripts. Qualitative data and raw themes were compared to check for congruency, patterns, and unique themes. Analysis of individual cases culminated with the creation of diagrams that summarized key relationships among flow and reversal theory for that participant. Cross-case analysis was performed by identifying common themes and comparing visual diagrams and data across the cases. If reoccurring themes or trends existed, the raw quotes associated with each theme were grouped together and reanalyzed to rule out discrepancies or inconsistencies. From this process, general patterns of experience were constructed that incorporated reported relationships among flow and reversal theory states.

\section{Results}

This section details cross-case analyses of key themes. Although individual cases highlighted the idiosyncratic nature of adventure experiences, cross-case analyses revealed clear patterns of reversal theory and flow states throughout the 
3-day course. Alternations between telic and paratelic states were described across all cases, particularly with regard to phases surrounding river rapids. Participants reported more serious-minded (telic) moods before a rapid followed by reversals to a more playful (paratelic) frame of mind following a rapid (see Figure 1). Participant reports of anxiety or seriousness prior to a rapid were sometimes interspersed with feelings of excitement, followed by playfulness and enjoyment after a rapid. These shifts (i.e., more serious to more playful) tended to occur before and after rapids that posed the highest levels of perceived challenge. Nina describes such shifts in emotional states:

I was pretty terrified...[and] fearful that my ability wouldn't get me through it... As soon as I got into the white water, I lose track of fear, just go for it and quite like it... I was just going with the flow... [After the rapid I felt] relaxed; [a] great sense of achievement; really excited; energized... I really enjoyed it.

The intensity and frequency of mood shifts were also reported to increase as the 3-day course progressed. Interviews suggested that these fluctuations were due to a number of factors, such as increasing levels of perceived challenge and personal responsibility, physical state (e.g., nutrition, fatigue), mental strategies, peer and instructor interactions, and satiation. Indeed, reversal theory researchers predict that the longer an individual is in one state, the more likely they are to reverse to an opposing state (i.e., satiation; Frey, 1999). These data indicated that the "felt intensity" of a metamotivational state may have also influenced participants' propensity to reverse, as they often reversed quickly between states when felt intensity levels were elevated.

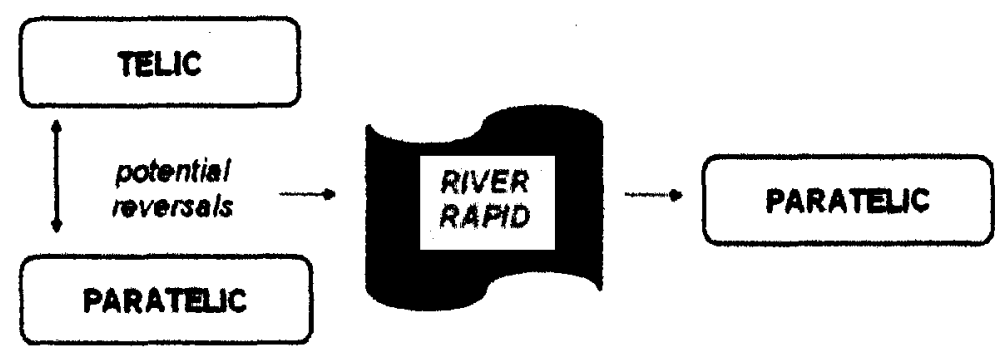

Figure 1. The Multiphasic Nature of Reversal Theory States in Relation to River Rapids 
Dan clearly articulated this process in his descriptions of relationships between fear and adrenaline: "By being scared, you create adrenaline, and then it's exciting and fun." This quote highlights how increased felt arousal and accompanying feelings of anxiety (i.e., the telic state) might be a necessary precursor to excitement and "fun" (i.e., the paratelic state). These case studies indicated that the phasic nature of the telic and paratelic states within adventure experiences may function symbiotically and that this phasic process might facilitate a range of flow experiences. Although this theme was present throughout the five cases, exceptions occurred when participants felt fatigued or perceived that challenges outweighed their skills. These situations appeared to instigate a more telic (seriousminded, arousal-avoidant) frame of mind either during or after these challenging river rapids.

\section{Influence of Physical State on Metamotivational States and Flow}

The influence of participants' physical state (e.g., fatigue, nutrition) on metamotivational states and flow was highlighted in each case study, as illustrated by Jenna's comment, "I wanted to feel energized and playful again, but I was really tired." The physically taxing nature of the activity influenced participants' mental focus, energy levels, and moods. For instance, on most mornings participants reported feeling sluggish, cold, and unmotivated. This may have been exacerbated by low mean air $\left(15.5^{\circ} \mathrm{C}\right)$ and water $\left(15.3^{\circ} \mathrm{C}\right)$ temperatures during the 3 -day course in March 2008 (National Institute of Water and Atmospheric Research, 2010) and because participants camped for the entire course. A similar trend was described toward the end of each day when participants reported focusing on eating and warming up, which appeared to influence their metamotivational states and flow opportunities.

Regardless of metamotivational state, a clear theme that echoed throughout the interviews was that initiation of action (e.g., entering the water) generally precipitated a reversal and/or a flow state. Nina noticed this tendency:

When I'm not doing something and I'm thinking about what it's going to be like, I get quite tense and think about it too much... Once [I am in the rapid]...I've got to go with the flow and do the best I can... I'm just focused on what's happening.

This mood change was generally positive, in the sense that participants felt more energized and motivated to take on challenges once they had initiated a course of action. Mitch and Dan illustrated this pattern in the following observations:

It's like I got in the water and [snaps fingers]...I wasn't nervous anymore. I pretty much forgot all about the rocks. (Mitch)

It was nothing like I expected at all... I just went with the flow and didn't think about it too much... That was quite relieving. (Dan)

These reports also suggested that flow may be instigated by metamotivational state reversals, which helped to account for the elevated moods reported when participants were engaged in an activity. 
For example, in the mornings when participants were tired and lacking in energy, jumping into the water appeared to change their mood instantly. Dan clearly asserted this change:

Soon as we were [in the water], I suddenly felt recharged... You've suddenly got something to do and it's refreshing... You are getting into it and... preparing your body for bigger challenges further on... [I enjoyed] the whole flow of it.

Participants reported that initiating action not only increased energy levels but also seemed to generate a sense of control in relation to new challenges. Nina described this feeling as "calm" yet "energized," a state that allowed her to mentally prepare for the challenge ahead. Thus, the initiation of action appeared to influence metamotivational reversals, as well as opportunities to experience flow.

\section{The Multiphasic Nature of Flow in Adventure Experiences}

Flow experiences appeared to occur in phases during this 3-day course. All five participants reported that their most intense flow experiences were preceded by a mix of emotions, especially in the context of more challenging rapids. Jenna's and Nina's data in particular highlighted how participants' most intense flow experiences were generally concurrent with their most intense mood changes. Novel situations and uncertainty appeared to prompt a mix of emotions, or frequent reversals between the telic and paratelic states, prior to flow. Dan, for instance, indicated that pleasant (e.g., excitement, enjoyment) and unpleasant (e.g., fear, apprehension) emotions were interdependent in that they were two sides of the same coin; in his opinion, one could not occur without the other:

Fear definitely increases the adrenaline...because if you are scared of something then your heart races, you get scared, sweaty palms... I was definitely scared at time...excited-scared... To me, they're kind of similar. I mean by being scared you create adrenaline and then it's exciting and it's fun... When you have to do it, that's part of the buzz... It's a rush doing it, but it's also thinking about it... It's the whole thing.

In the first quote presented in the results section, Nina also demonstrated the multiphasic nature of flow experiences by describing how contrasting emotions complemented each other to facilitate intense flow experiences. These sentiments were reiterated throughout the case studies across various situations, as demonstrated by Tenzin's account: "I was worried before I jumped in. Once I jumped in, I was pretty excited. Once I got down the [rapid], I was on top of the world!" Reversals between serious-mindedness and playfulness and fluctuations in felt arousal levels appeared to provide optimal enjoyment and satisfaction throughout the course because this allowed participants to overcome fears, accomplish goals, build confidence for future challenges, and experience relaxation and fun. Some descriptions in Mitch, Jenna, Tenzin, and Dan's cases also suggested that reversals might potentially occur within the state of flow itself. Mitch observed, "I was more confident...so I was able to have more fun...trying to do little rolls." Participants often began an activity with an intense telic focus and, upon performing that task successfully, they relaxed and sometimes attempted to "play around" or increase challenges (e.g., perform a "trick"). 
Participants' descriptions of flow across these cases varied in terms of their phases, qualities, and intensities. As illustrated in Figure 2, the case studies revealed instances in which (a) the paratelic state appeared to dominate prior to flow (paratelic flow; Dan, Mitch, Jenna), (b) the telic state appeared to dominate prior to flow (telic flow; Dan, Mitch, Nina), and (c) flow was preceded by frequent telic-paratelic reversals (Dan, Mitch, Nina, Tenzin, Jenna).

Surfing descriptions in particular highlighted that flow experiences characterized by important outcomes (e.g., catching a wave in front of others) were often precipitated by the telic state (see Figure 2). The seriousness of the telic state also appeared to facilitate the heightened focus necessary for flow, as described by Tenzin in the following quotes: "I was pretty anxious of what [was] going to happen... I'm thinking: I have to try and do this [surf the wave]... Once I got [on the wave], time [went] pretty quickly." This flow state appeared to depend upon task success and was initially followed by a paratelic state of heightened excitement ("I [was] like 'yes!'...pretty excited"), which was followed by a telic state of enjoyment and satisfaction at lowered intensity levels.

After a challenge, I like that relaxing time of not having to think and just being able to reflect on what you just did... That's why I didn't find it boring... Whereas if [the easy task] had been at the beginning, I would probably be...bored." (Tenzin)

Heightened Felt IntensityIArousal Telic Flow

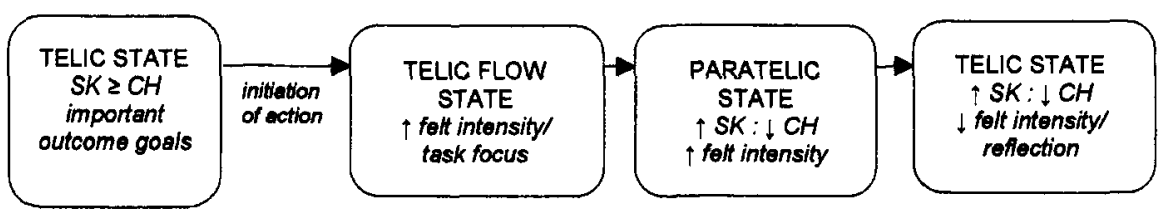

Helghtened Felt Intensity/Arousal Paratelic Flow

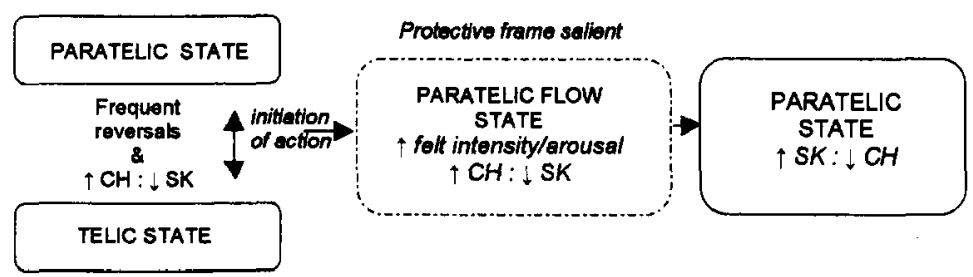

Leqend:

$\mathrm{CH}=$ Perceived Challenges

SK = Perceived Skills

$\uparrow=$ Heightened

$\downarrow=$ Lowered

Lowered Felt Intensity/Arousal Paratelic Flow

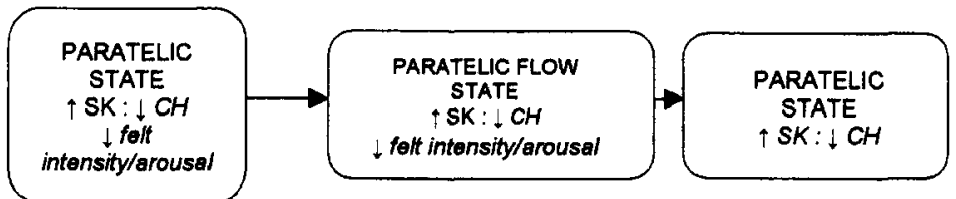

Figure 2. Basic Conceptual Models of Flow Phases Characterized by Telic and/or Paratelic States 
Participants also reported distinct flow experiences that were characterized by more playful and process-focused phases. These phases were reported in activities with less specific goals and were often characterized by a sense of protection from hazards created by the paratelic protective frame and other dimensions (e.g., sensation or arousal seeking) of the flow experience beyond challenge and skill perceptions. Some of these instances occurred when participants encountered heightened challenge levels that were potentially emotionally distressing (e.g., a grade 4 rapid), not merely physically difficult (e.g., surfing). In these episodes, the arousal-seeking aspect of the paratelic state appeared more salient than the playful aspect due to the potentially serious consequences present, and participants reported rapidly alternating phases of the telic (i.e., anxiety) and paratelic (i.e., excitement) states prior to experiencing flow (see Figure 2). Such phase shifts are illustrated in the following observations:

[I was] flipping...between nervousness and anxious and excited. They switch so you feel one and then the other. (Jenna)

What made it the best...was one extreme emotion beforehand and then [another] as you're accomplishing what you were just freaking out about, that was the best... [Overcoming fear] made it enjoyable...more adventurous...because I felt so nervous and I wasn't quite sure if I could do it... That's what gave me the greater sense of achievement. (Nina)

Paratelic states of lowered intensity were generally reported after these powerful experiences. This phase was then often followed by a telic reversal (e.g., wanting to get out of the river) as a result of satiation (e.g., of the arousal-seeking aspect of the paratelic state). Nina's report below reflected these phases:

I was so determined to get to that other side, so focused on that task...the whole time I was fully immersed in what was happening... It wasn't until I realized where I was... then I was sort of able to relax...and enjoy what I was getting through... [Afterwards] I was really tired... I just wanted to... get back to camp.

These examples of paratelic flow were characterized by phases of heightened intensity, potentially due to the elevated arousal levels reported, and were generally followed by a pleasant, reflective state of relaxation (i.e., playful with a lowered level of arousal seeking).

Lower intensity phases of flow were also reported in relation to less challenging river sections, as evidenced by Jenna's description: "I think Dog Leg [rapid] and...Do-Little [grade $2 / 3$ rapids were] more of a relaxed enjoyment...more of a 'pleasant enjoyable'...'calmer enjoyable' [than the grade 4 rapid]." Nina echoed these sentiments in relation to a less challenging rapid: "[The grade 2 rapid] was fun actually!... I enjoyed it... The water was pretty calm... I was pretty confident." As exemplified in the following quote, participants described these flow phases as playful and fun rather than as scary or challenging: "When I'm...playful, l'm doing [an activity] for fun, recreation, in the moment. Just in flow" (Tenzin).

Qualitative accounts of participants' experiential phases were essential to understanding how and why these phases occurred. Rather than merely describing 
a sequence of states, these data provided a nuanced understanding of how these phases facilitated holistic adventure experiences. The data below indicated not only that adventure experiences and flow occurred in distinct phases, but also that "opposing" experiential phases were symbiotic and integral to participants' overall enjoyment of the adventure experience:

Everything in balance keeps me happy... If I stayed excited too long, I'd get bored of getting excited, and if I was calm too long, I would get bored of being calm... I need that change. (Mitch)

I always need a challenge, but then have time to chill out and then reflect on that challenge... Chilling out this afternoon [Day 2] was a good time to reflect... and set myself up for [Day 3]... [It gave me] assurance that I've rested and thought about everything...a sense of calm. (Jenna)

I like a variety of emotions... I went through an exciting phase, had a relaxing bit, and then my anxiousness [increased] again because I wanted to get excited again. (Nina)

When you get excited, you're not really thinking a lot; your mind is completely focusing on what's going on at the moment. But once you're calm...you get to debrief yourself on what's just happened...you just get some peace and quiet with yourself. And then you feel playful again after that... It's just a flow that happens. Like [we] were just fooling around ... so that was playfulness and then once the guide says that there's a rapid coming up again, there's a tad bit of attentiveness...seriousness...paying attention. And then again, "yes!" Adventure, excitement, thrill. (Tenzin)

\section{Other Infiuences on Reversal Theory States}

Cross-case analysis also revealed that environmental influences, such as guide instructions and weather, might have contributed to reversal theory state changes. For instance, communication between guides and clients (e.g., during safety talks) appeared to instigate the telic state by increasing hazard awareness and decreasing the salience of participants' paratelic protective frames, as observed by Dan:

When you stop and talk about things, it makes it a little more prevalent what you're about to do. So talking about it and saying it's quite a high grade rapid...it did amp you up... [The guide] starts pointing out hazards and you're like "oh man!"... We were made to feel responsible for what we were doing... I think the [guides] talked it up more that it was... The rapid was nowhere near as scary as I expected.

Participants also indicated that changes in environmental conditions, such as heavy rains that changed the river color, might have instigated reversals to the telic state.

The river felt more...foreign... I was surprised how much the water had changed... We could see it was really dark and murky... [I felt] worried and [a] little bit nervous. (Dan) 
I really enjoyed Dog Leg [rapid] in the morning, [but] it changed later on in the evening as the water went higher. (Tenzin)

\section{Discussion}

These results indicated that participants' adventure experiences were characterized by metamotivational and emotional phases that corresponded to key dimensions of flow and the telic and paratelic states, respectively. Specifically, participants reported being in the telic state at the start and finish of each day and that the telic state generally preceded rapids and other perceived challenges. The paratelic state was often reported to ensue after participants initiated an action or completed a challenging task. Frequent telic-paratelic reversals were also reported prior to highly challenging tasks.

\section{Relationships Between Flow and Metamotivational States}

Participants reported a range of flow states that appeared to be related to different metamotivational state phases. They described flow episodes that were preceded by the telic state and the paratelic state, respectively, and reported that differences in phases surrounding flow may have facilitated distinct flow dimensions. Although flow was an integral phase of the adventure experience, it appeared to have different manifestations (e.g., telic flow and paratelic flow) depending on the phase and context in which it occurred. Overall, distinct flow states, metamotivational state reversals, and contextual variables (e.g., physical state, natural environment) appeared to better define significant phases of participants' adventure experiences than chronological phases identified in previous research (e.g., Clawson \& Knetsch, 1966). These findings indicated that reversal theory and flow measures could be effectively used to operationalize key phases of adventure experiences.

\section{Multiphasic Experiences and Enjoyment}

In line with reversal theory tenets, an overall balance of telic and paratelic state phases (and felt intensities of these states), appeared ideal in terms of holistic experience quality and overall enjoyment. Continually shifting phases of emotions and intensities were reportedly preferred to a single emotional state. Participants also reported that state changes occurred more quickly at heightened levels of felt intensity. Intense experiential phases appeared to generate the desire to experience an opposing phase (e.g., periods of intense anxiety or excitement generated the desire for relaxation). Thus, the dynamic tensions between opposing phases appeared to be a key element driving the multiphasic nature of participants' experiences. This finding has implications for the sequencing of leisure activities at heightened and lowered arousal levels and elucidates findings that seemingly "opposing" emotions were reported to occur simultaneously within leisure experiences (Hull et al., 1992).

In line with previous research (Patterson et al., 1998), this study noted the importance of a reflective phase of lowered intensity, during which participants analyzed experiences, following an "intense" activity. In contrast to previous research, however, these fluctuations were identified at various phases within the experience rather than solely at the end of an experience. Data also highlighted that 
the contrast between opposing states left participants with a sense of enjoyment upon completion of an activity. Future research should therefore further investigate the role of opposing phases, with particular attention to lower intensity reflective phases within an experience, and the effect of dynamic tensions between opposing phases in promoting overall enjoyment. The frequency and intensity of these phases not only may influence immediate enjoyment but also could be potentially linked to longer term participation and learning over longer time spans.

\section{Dynamic Tensions Within Adventure Experiences}

These findings supported a multiphasic model of adventure experiences and flow comprising distinct telic and paratelic dimensions at varying intensities, which interacted in a dynamic, synergetic manner. Dynamic tensions between paratelic and telic state dimensions, and accompanying challenge and skill perceptions, appeared to account for the multiphasic nature of flow and enjoyment identified in this project. Enjoyment within the adventure experience also appeared to comprise distinct yet symbiotic motivational components because it reportedly depended upon optimal alternation of opposing states across a range of intensities and challenge and skill perceptions. A balance of positive and negative psychological states seemed to be integral to participants' overall enjoyment of the adventure experience. This synergy was evident across the cases in that participants' most powerful, and ultimately most enjoyable, experiences were reported when intense positive and negative emotional states were juxtaposed. This juxtaposition appeared to create essential dynamic tensions between telic and paratelic state dimensions.

\section{Future Research}

Accounting for the multiphasic nature of flow and adventure by clarifying key phases based on reversal theory states, and environmental influences on those states, could increase our understanding of the mechanisms underpinning the development of increasing complex flow states and longer term participation in adventure activities. These approaches can facilitate adventure-based flow research that extends beyond traditional flow measurements (e.g., a challenge-skill balance) and may increase empirical support for the hypothesized long-term influences of flow on participation and talent development (e.g., Csikszentmihalyi, 1993). Specifically, a multiphasic approach could be used to guide investigations of flow and adventure experiences, such as (a) flow and adventure lifestyles, (b) longitudinal changes in phases of adventure experiences, (c) flow complexity, (d) the relationship between flow and different phases of the learning process, and (e) flow in relation to longer term participation and talent development. These approaches could also be used to expand recreation and tourism research that seeks to identify and measure visitor experiences and adjust offerings accordingly.

This study suggested that phases of adventure experiences should be measured subjectively (e.g., via measures of motivational states and emotions), as this is more likely to yield useful indicators of phase changes, rather than through objective observations of time or environmental changes (e.g., grade 1 vs. grade 4 white water). Notwithstanding participants' reports that the environment, physical changes, and interpersonal communications affected their experience, these factors appeared to be moderated by subjective interpretations of these elements, 
which then led to changes in metamotivational and emotional phases of an experience. Thus, objective measures appeared to be a more distal indicator of phase changes than subjective interpretations of motivational states. Future research should therefore emphasize the measurement of motivational states when investigating the multiphasic nature of adventure experiences, rather than the objectively observable changes in the environment, and employ reversal theory measurement tools (e.g., the Telic/Paratelic State Instrument; O'Connell \& Calhoun, 2001) to expand a multiphasic model of adventure experiences and flow.

The role of social interactions in instigating reversals, constructing and dispelling protective frames, and facilitating or inhibiting flow should also be purposefully examined in future adventure literature. Improved understanding of the social context in which these states unfold, such as the relative influence of guides and peers on danger perceptions, could inform best practice and training policies for river operators and other adventure practitioners. A symbolic interaction perspective (e.g., Holyfield \& Jonas, 2003; Jonas, 1999) could provide an informative theoretical framework from which to investigate and better understand these influences on reversal theory and flow states in future research.

\section{Conclusion}

This project expanded upon past multiphasic research insofar as it identified phases of flow within a reversal theory framework and offered more precise ways to operationalize phases of adventure experiences. It also highlighted the symbiotic nature of distinct "opposing" phases and the role of dynamic tensions between paratelic and telic state dimensions in facilitating optimal fluctuations in phases throughout adventure experiences. Our findings suggested that these mechanisms might account for the dynamic nature of enjoyment, flow, and motivational states within an adventure experience. Future research should seek to validate the phasic models suggested herein and evaluate their potential applicability to other adventurous activities.

\section{References}

Apter, M. J. (1982). The experience of motivation: The theory of psychological reversals. London, England: Academic Press.

Apter, M. J. (1989). Reversal theory: Motivation, emotion and personality. London, England: Routledge.

Apter, M. J. (1992). The dangerous edge: The psychology of excitement. New York, NY: Free Press.

Apter, M. J. (1993). Phenomenological frames and the paradoxes of experience. In J. H. Kerr, S. J. Murgatroyd, \& M. J. Apter (Eds.), Advances in reversal theory (pp. 27-39). Amsterdam, Netherlands: Swets \& Zeitlinger.

Apter, M. J. (Ed.). (2001). Motivational styles in everyday life: A guide to reversal theory. Washington, DC: American Psychological Association.

Apter, M. J., \& Batler, R. (1997). Gratuitous risk: A study of parachuting. In S. Svebak \& M. J. Apter (Eds.), Stress and health: A reversal theory perspective (pp. 119-129). Washington, DC: Taylor \& Francis. 
Apter, M. J., Mallows, R., \& Williams, S. (1998). The development of the Motivational Style Profile. Personality and Individual Differences, 24(1), 7-18.

Borrie, W. T., \& Roggenbuck, J. W. (2001). The dynamic, emérgent, and multi-phasic nature of on-site wilderness experiences. Journal of Leisure Research, 33(2), 202-228.

Breejen, L. (2007). The experiences of long distance walking: A case study of the West Highland Way in Scotland. Tourism Management, 28(6), 1417-1427.

Carli, M., Delle Fave, A., \& Massimini, F. (1988). The quality of experience in the flow channels: Comparison of Italian and U.S. students. In M. Csikszentmihalyi \& I. S. Csikszentmihalyi (Eds.), Optimal experience: Psychological studies of flow in consciousness (pp. 288-306). New York, NY: Cambridge University Press.

Ceja, L., \& Navarro, J. (2009). Dynamics of flow: A nonlinear perspective. Journal of Happiness Studies, 10(6), 665-684.

Clawson, M., \& Knetsch, J. L. (1966). Economics of outdoor recreation. Baltimore, MD: Johns Hopkins Press.

Cogan, N., \& Brown, R. (1999). The experience of risk sport: Dominance, states and injuries. In J. H. Kerr (Ed.), Experiencing sport: Reversal theory (pp. 155-174). New York, NY: John Wiley \& Sons.

Csikszentmihalyi, M. (1975). Beyond boredom and anxiety. San Francisco, CA: Jossey-Bass.

Csikszentmihalyi, M. (1993). The evolving self. New York, NY: Harper \& Rowe.

Csikszentmihalyi, M., \& Csikszentmihalyi, I. S. (1990). Adventure and the flow experience. In J. C. Miles \& S. Priest (Eds.), Adventure education (pp. 149-155). State College, PA: Venture.

Csikszentmihalyi, M., \& Larson, R. (1987). Validity and reliability of the Experience-Sampling Method. Journal of Nervous and Mental Disease, 175(9), 526-536.

Denzin, N. K., \& Lincoln, Y. S. (Eds.). (2005). The Sage handbook of qualitative research (3rd ed.). Thousand Oaks, CA: Sage.

Ferrero, F. (2006). Whitewater safety and rescue (2nd ed.). Gwynedd, Wales: Pesda Press.

Frey, K. P. (1999). Reversal theory: Basic concepts. In J. H. Kerr (Ed.), Experiencing sport: Reversal theory (pp. 3-17). New York, NY: John Wiley \& Sons.

Holyfield, L., \& Jonas, L. (2003). From river guide to river grunt: Identity, emotions, and the river guide. Symbolic Interaction, 26(2), 285-306.

Houge Mackenzie, S., Hodge, K., \& Boyes, M. (2011). Expanding the flow model in adventure activities: A reversal theory perspective. Journal of Leisure Research, 43(4), 519-544.

Hull, R. B., Stewart, W. P., \& Yi, Y. K. (1992). Experience patterns: Capturing the dynamic nature of a recreation experience. Journal of Leisure Research, 24(3), 240-252.

Jackson, S. A., \& Eklund, R. C. (2004). The Flow Scales manual. Morgantown, WV: Fitness Information Technology.

Jonas, L. (1999). Making and facing danger: Constructing strong character on the river. Symbolic Interaction, 22(3), 247-267.

Jones, C., Hollenhorst, S., \& Perna, F. (2003). An empirical comparison of the Four Channel Flow Model and Adventure Experience Paradigm. Leisure Sciences, 25(1), 17-31. 
Kerr, J. H. (1985). The experience of arousal: A new basis for studying arousal effects in sport. Journal of Sports Sciences, 3, 169-179.

Kerr, J. H. (1989). Anxiety, arousal, and sport performance: An application of reversal theory. In D. Hackfort \& C. D. Spielberger (Eds.), Anxiety in sports: An international perspective (pp. 137-151). New York, NY: Hemisphere.

Kerr, J. H. (1991). Arousal seeking in risk sport participants. Personality and Individual Differences, $12(6), 613-616$.

Kerr, J. H. (1994). Understanding soccer hooliganism. Buckingham, England: Open University Press.

Kerr, J. H. (1999a). Motivation and emotion in sport: Reversal theory. Hove, England: Psychology Press.

Kerr, J. H. (Ed.). (1999b). Experiencing sport: Reversal theory. New York, NY: John Wiley \& Sons.

Kerr, J. H., \& Apter, M. J. (Eds.). (1991). Adult play: A reversal theory approach. Amsterdam, Netherlands: Swets \& Zeitlinger.

Kerr, J. H., \& Cox, T. (1991). Arousal and individual differences in sport. Personality and Individual Differences, 12(10), 1075-1085.

Kerr, J. H., Fujiyama, H., \& Campano, J. (2002). Emotion and stress in serious and hedonistic leisure sport activities. Journal of Leisure Research, 34(3), 272-289.

Lachenicht, L. (1988). A critical introduction to reversal theory. In M. J. Apter, J. H. Kerr, \& M. P. Cowles (Eds.), Progress in reversal theory (pp. 1-42). Amsterdam, Netherlands: Elsevier Science.

Lee, B., \& Shafer, C. S. (2002). The dynamic nature of leisure experience: An application of Affect Control Theory. Journal of Leisure Research, 34(3), 290-310.

Lee, Y., Dattilo, J., \& Howard, D. (1994). The complex and dynamic nature of leisure experience. Journal of Leisure Research, 26, 195-211.

Males, J. (1999). Individual experience in slalom canoeing. In J. H. Kerr (Ed.), Experiencing sport: Reversal theory (pp. 101-128). New York, NY: John Wiley \& Sons.

Martin, R. A., Kuiper, N. A., Olinger, L. J., \& Dobbin, J. (1987). Is stress always bad? Telic versus paratelic dominance as a stress-moderating variable. Journal of Personality and Social Psychology, 53(5), 970-982.

Massimini, F., Csikszentmihalyi, M., \& Delle Fave, A. (1988). Flow and biocultural evolution. In M. Csikszentmihalyi \& I. S. Csikszentmihalyi (Eds.), Optimal experience: Psychological studies of flow in consciousness (pp. 60-84). Cambridge, England: Cambridge University Press.

McIntyre, N., \& Roggenbuck, J. W. (1998). Nature/person transactions during an outdoor adventure experience: A multi-phasic analysis. Journal of Leisure Research, 30(4), 401-422.

Nakamura, J., \& Csikszentmihalyi, M. (2005). The concept of flow. In C. R. Snyder \& S. J. Lopez (Eds.), Handbook of positive psychology (pp. 89-105). Oxford, England: Oxford University Press.

National Institute of Water and Atmospheric Research. (2010). The National Climate Database: Retrieved July 15, 2010, from http://cliflo.niwa.co.nz

O'Connell, K. A., \& Calhoun, J. E. (2001). The Telic/Paratelic State Instrument (T/PSI): Validating a reversal theory measure. Personality and Individual Differences, 30(2), 193-204. 
O'Connell, K. A., Cook, M. R., Gerkovich, M. M., Potocky, M., \& Swan, G. E. (1990). Reversal theory and smoking: A state-based approach to ex-smokers' highly tempting situations. Journal of Consulting and Clinical Psychology, 58(4), 489-494.

O'Connell, K. A., Potocky, M., Cook, M. R., \& Gerkovich, M. M. (1991). Metamotivational state interview and coding schedule instruction manual. Kansas City, MO: Midwest Research Institute.

Omodei, M., \& McLennan, J. (1994). Studying complex decision making in natural settings: Using a head-mounted video camera to study competitive orienteering. Perceptual and Motor Skills, 79, 1411-1425.

Pain, M. T., \& Kerr, J. H. (2004). Extreme risk taker who wants to continue taking part in high risk sports after serious injury. British lournal of Sports Medicine, 38, 337-339.

Patterson, M. E., Watson, A. E., Williams, D. R., \& Roggenbuck, J. R. (1998). An hermeneutic approach to studying the nature of wilderness experiences. Journal of Leisure Research, 30(4), 423-452.

Rea, D. (1993). Reversal theory explanations of optimal experience. In J. H. Kerr, S. J. Murgatroyd, \& M. J. Apter (Eds.), Advances in reversal theory (pp. 75-88). Amsterdam, Netherlands: Swets \& Zeitlinger.

Stewart, W. P., \& Hull, B. R. (1996). Capturing the moments: Concerns of in-situ leisure research. Journal of Travel and Tourism Marketing, 5, 3-20.

Svebak, S., Nordby, H., \& Ohman, A. (1987). The personality of the cardiac responder: Interaction of serious-mindedness and type A behavior. Biological Psychology, 24,

Wyer, R. S., \& Collins, J. E. (1992). A theory of humor elicitation. Psychological Review, 99, 663-688. 